\title{
О границе между хрупким и пластичным состояниями земной коры
}

\author{
Жамалетдинов А.А. ${ }^{1,2}$ \\ ${ }^{1}$ Санкт-Петербургский филиал ИЗМИРАН, Санкт-Петербург, abd.zham@таil.ru \\ ${ }^{2}$ Геологический институт КНЦ РАН, Апатить
}

Аннотация. В статье рассмотрены современные представления о реологии континентальной земной коры, опирающиеся на петрофизические данные и результаты численного моделирования. Приведены количественные оценки положения границы перехода кристаллических пород из хрупкого в квазипластичное состояние на основе результатов глубинных электромагнитных зондирований и сверхглубокого бурения.

Ключевые слова: реология, электромагнитное зондирование, хрупкость, пластичность, бурение.

\section{On the boundary between the brittle and ductile states of the Earth's crust}

\author{
Zhamaletdinov A.A. ${ }^{1,2}$ \\ ${ }^{1}$ St. Petersburg branch of IZMIRAN, St.Petersburg, abd.zham@mail.ru \\ ${ }^{2}$ Geological Institute, KSC RAS, Apatity
}

\begin{abstract}
The modern ideas about the rheology of the continental crust are discussed on the base of petrophysical data and results of numerical modeling. New data on the location of the brittle-ductile transition (BDT) boundary are presented based on results of the deep electromagnetic soundings and super deep hole drilling.

Key words: rheology, electromagnetic sounding, brittle, ductily, super-deep drilling.
\end{abstract}

Теорию хрупкого состояния земной коры первым начал развивать академик М.А. Садовский в своих работах, посвященных проблеме «кусковатости» земной коры (Садовский, 1945). Кусковатость он рассматривал как многоразмерную отдельность структурных звеньев земной коры по типу самоподобных фрактальных структур. Эта идея нашла свое продолжение в работах, посвященных анализу напряженно-деформированного состояния среды (Гзовский, 1975; Николаевский 1996).

Последующие исследования реологических свойств геологической среды проводились путем компьютерного моделирования с учетом широкого набора петрофизических и геофизических параметров (упругости, плотности, магнитных свойств, геотермии, теплогенерации и др.). Результаты моделирования позволили составить представление о многослойном строении земной коры и верхней мантии в виде чередования слоев хрупкого («brittle») и вязкого («ductile») состояния (Ranalli, 1993; Moisio \& Kaikkonen, 2004; Глазнев, 2003). В основе уравнений реологии лежат априорные данные о внутренних и внешних свойствах среды и окружающего пространства. Поведение горных пород при этом происходит по двум сценариям - в виде хрупкой деформации (brittle) и в виде пластического (вязкого) течения (ductile). Поведение геоматериала при хрупкой деформации рассчитывается по кулоновскому закону (Глазнев, 2003; Moisio, 2005).

$$
\sigma 1-\sigma 3=\beta(1-\lambda) P(z),
$$

где $\sigma 1$ - максимальное и $\sigma 3$ - минимальное напряжение, $P(z)$ - литостатическое давление, $\beta$ - коэффициент статического трения и $\lambda$ - отношение корового и литостатического трения.

Если геоматериал обнаруживает способность к течению под действием сдавливающих (или растягивающих) напряжений, то его поведение в режиме медленного, установившегося течения (дислокационного крипа, ползучести) принято описывать уравнением (2) (Kirby \& Kronenberg, 1987)

$$
\sigma 1-\sigma 3=\left(\frac{\mathbb{E}}{A_{p}}\right)^{1 / n} \cdot e^{E_{p} / n \cdot R \cdot T(z)}
$$

где $\&$ - скорость деформации $\left(c^{-1}\right), n$ и $A_{p}$ - экспериментально определяемые параметры для заданного типа геоматериала, $E_{p}$ - энергия активации (Дж/Mоль), $R$ - универсальная газовая постоянная (8.31 Дж/(Моль $K), T(z)$ - абсолютная температура в зависимости от глубины, $K$ - один градус Кельвина. 


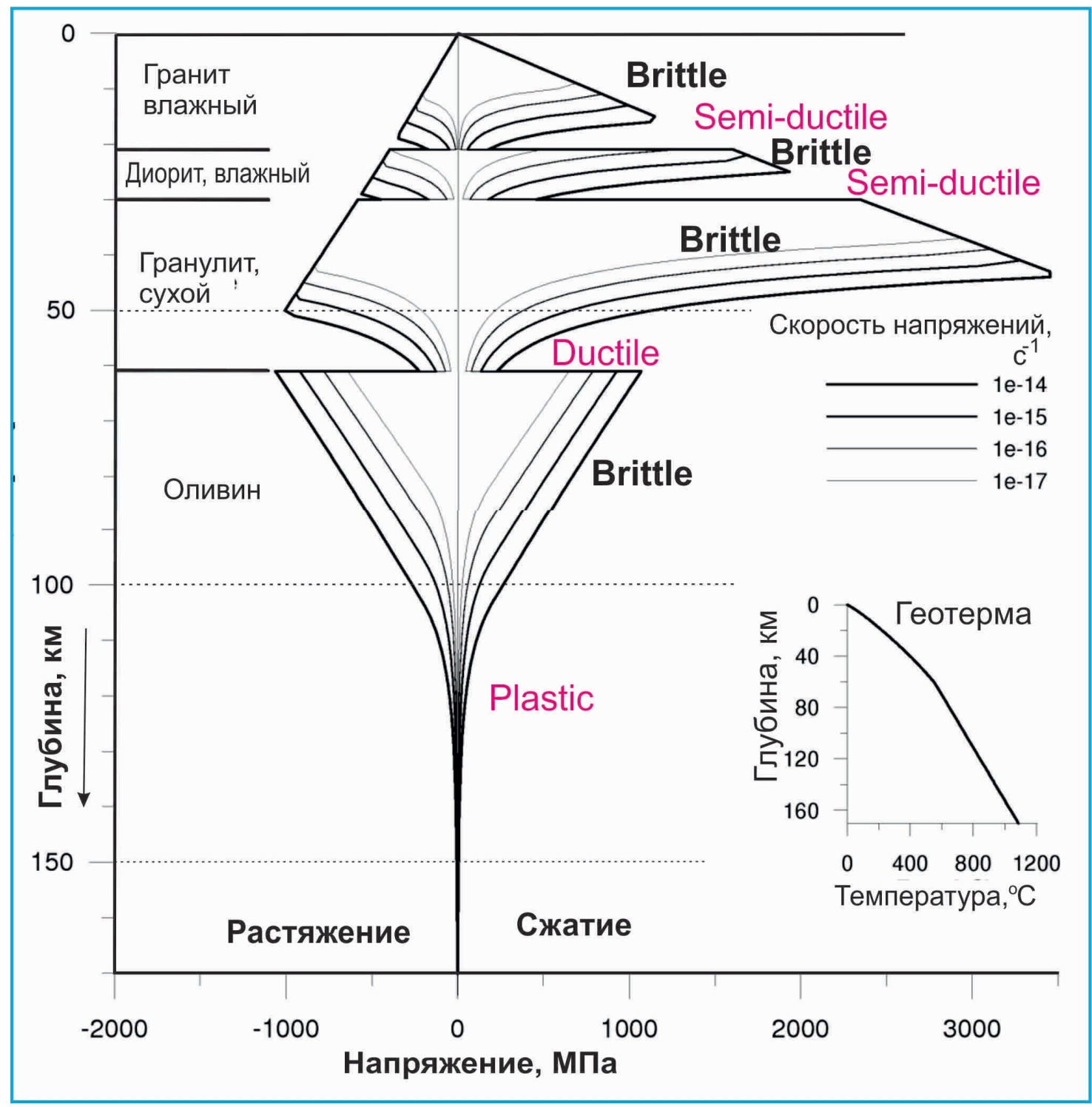

Рис. 1. Реология литосферы Фенноскандинавского щита по (Moisio, 2005).

Fig. 1. The rheology of the Fennoscandian Shield lithosphere after (Moisio, 2005).

Область, в которой данный материал разрушается путем хрупкого воздействия (fracturing), называется «brittle zone». Условия, при которых геоматериал находится в состоянии пластического течения, называются «ductile zone». Один и тот же материал, в зависимости от задаваемых параметров в уравнениях (1) и (2), может испытывать условия как «brittle», так и «ductile» трансформации.

Не вдаваясь в дальнейшее рассмотрение уравнений и априорных параметров, применяемых в реологии, обратимся к рисунку 1 , где приведены результаты моделирования условий перехода геоматериала из хрупкого (brittle) в пластичное (ductile) состояние (Brittle-Ductile Tranzitions, BDT) в пределах земной коры и верхней мантии (Moisio, 2005).

Самая верхняя граница на рисунке 1 (semi-ductile zone) варьирует в диапазоне от 10 до 20 км в зависимости от скорости деформации и фактически сливается с залегающей ниже brittle zone, простирающейся до глубины 30 км.

Примером расчета реологических параметров литосферы Фенноскандинавского щита и его обрамления являются результаты комплексных геофизических исследований, выполненных в работе (Глазнев, 2003) (рис. 2).

Расчеты, иллюстрированные (рис. 2) выполнены в предположении о земной коре, состоящей из двух слоев - верхнего (среднего состава) и нижнего (основного состава). Приняты две модели 


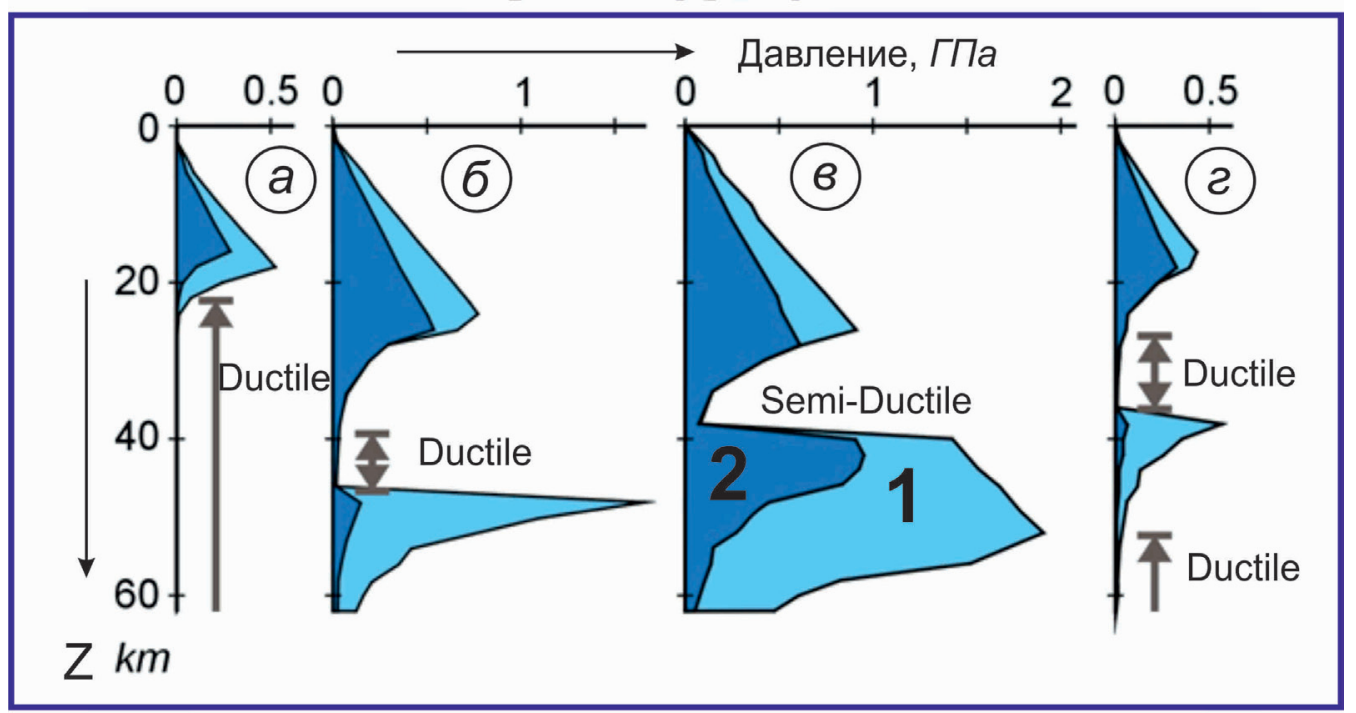

Рис. 2. Реологические профили литосферы, по (Глазнев, 2003).

a - Северная Атлантика; б - Свекофенская провинция; в - Беломорский террейн; г- Баренцевоморская плита; 1 - сухая литосфера; 2 - влажная литосфера; стрелками показаны области пластических (ductile) деформаций.

Fig. 2. Rheological profiles of the lithosphere.

a - North Atlantic; 6 -Svekofenian province; в - White Sea Terrane; г-Barents Sea plate; 1 - dry lithosphere; 2 - wet lithosphere; 3 - areas of ductile deformations.

разреза - абсолютно сухая (1) и влажная (2). Можно видеть, что реологические профили разных авторов на рисунках 1 и 2 существенно различаются между собой, несмотря на то, что в обоих случаях расчеты производились с использованием одних и тех же уравнений (1-2), приведенных выше.

Некоторые количественные оценки реологического состояния литосферы позволяют получать результаты мониторинга очаговых зон землетрясений. По этим данным до 80 процентов землетрясений сосредоточены в пределах верхних 10-20 км земной коры (Korhonen \& Porkka 1981, Шаров, Митрофанов, 2014), которая считается хрупкой.

При количественных оценках положения реологических границ в кристаллической земной коре определенные ожидания связывались с геоэлектромагнитными методами. Предполагалось «а priori», что реологические границы должны сопровождаться скачкообразными увеличениями электропроводности (Ваньян, 1997). В настоящей статье обосновывается возможность существования геофизической границы в виде плохо проводящего слоя на глубине 10-15 км. Первые экспериментальные указания на это, были получены в ходе проведения МГД-эксперимента «Хибины» (Геоэлектрические..., 1989). Была выдвинута гипотеза о двухслойном строении докембрийской кристаллической земной коры по электропроводности (Жамалетдинов, 1990). Вслед за Я. Седергольмом было сделано предположение, что верхний, более проводящий слой кристаллической земной коры представляет собой супракрустальную кору (супракору), сложенную метаморфизованными первично-осадочными и вулканогенными породами. Ниже залегает плохо проводящий протофундамент, сформированный на ранней, нуклеарной стадии развития Земли. Основным показателем двухслойного строения земной коры явились так называемые «токопроводящие» каналы (ТК), представленные электронно-проводящими сульфидно-углеродистыми породами. Их протяженность на глубину не превышает 10 км (Жданов, Френкель, 1983; Жамалетдинов и др., 1980).

Последующие эксперименты по глубинному зондированию с промышленными линиями электропередачи (Жамалетдинов, 2015; Shevtsov, 2019) привели к необходимости развития альтернативной, «физической» модели строения земной коры, в дополнение к геологической. Согласно новым данным было сделано предположение, что земная кора подразделяется на верхнюю хрупкую толщу, характеризующуюся резкой горизонтальной электрической неоднородностью и нижнюю 
квази-пластичную толщу, отличающуюся высоким сопротивлением и высокой горизонтальной однородностью. Между геологической и физической моделями сохраняются черты преемственности.

Полученное по результатам электромагнитных зондирований предположение о двухслойном строении земной коры нашло косвенное подтверждение в результатах бурения Кольской сверхглубокой скважины СГ-3. Все четыре попытки Кольской СГ-3 достигнуть желаемой «границы Конрада» в каждом случае заканчивались аварией бурового инструмента на одной и той же глубине забоя порядка 12 км. Буровики, выполнявшие проходку скважины СГ-3, объясняли причину аварий резким увеличением прочности (вязкости) горных пород на соответствующей глубине. Этот внешне негативный результат позволил сделать положительный вывод о том, что Кольская СГ-3 успешно выполнила свою основную задачу и достигла «границы Конрада», которая выразилась не в изменении химизма горных пород от кислых к основным, а в изменении физического состояния горных пород, в виде границы «непреодолимости» на глубине порядка 12 км. Эта граница близко совпадает по глубине с границей увеличения электрического сопротивления, описанной по результатам зондирований с мощными контролируемыми источниками.

Для получения более надежных количественных сведений об электрических параметрах границы BDT (Brittle-Ductile Transition Zone - граница «непроницаемости» между хрупким и пластичным состояниями кристаллической земной коры) выполнен эксперимент «Мурман-2018» по глубинному дистанционному электрическому зондированию (ДЭЗ) на постоянном токе на территории Мурманского блока. Схема проведения эксперимента и предварительные результаты приведены в работе (Жамалетдинов и др., 2019). Результаты эксперимента в виде кривых кажущегося электрического сопротивления ДЭЗ приведены ниже на рисунке 3 б.

На рисунке 3 а приведены результаты ранее выполненного зондирования на постоянном токе с установками ВЭЗ, Зевс» и МГД- «Хибины» (Zhamaletdinov, 2015). По результатам обоих экспериментов установлена трехслойная модель строения земной коры типа «А» с градиентно-ступенчатым увеличением удельного сопротивления. Результаты инверсии данных обоих экспериментов приве-

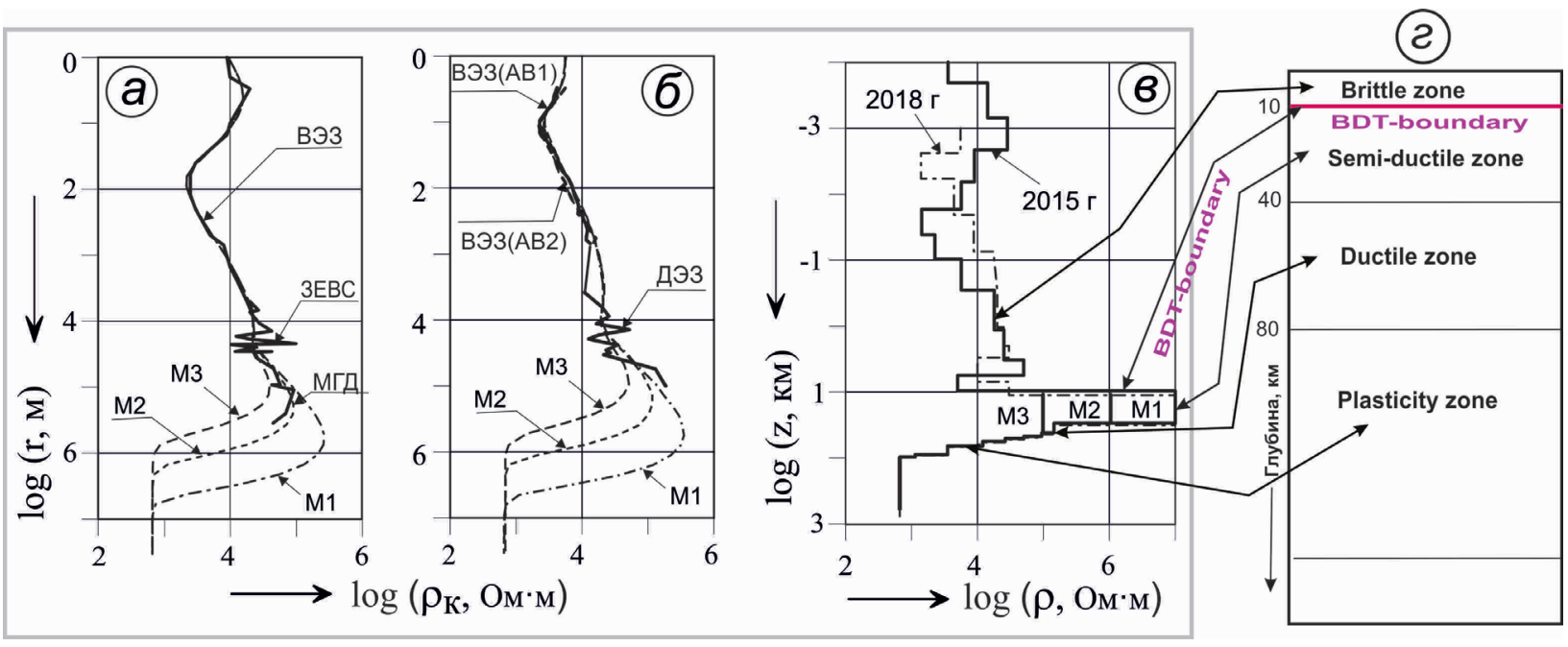

Рис. 3. Результаты дипольных электрических зондирований (ДЭЗ) на территории Мурманского блока. a - эксперимент «ВЭЗ-ЗЕВС-МГД» (Жамалетдинов, 2015); б - эксперимент «Мурман-2018» (Жамалетдинов и др., 2019); в - геоэлектрические разрезы и модели М1, М2, М3. Кривые $\rho_{\hat{e}}$ для моделей М1-М3 приведены на рис. 3 а и 3 б; г-реологический профиль, поясняющий результаты инверсии, приведенной на рис. 3 в. Остальные пояснения даны в тексте.

Fig. 3. The results of dipole electrical soundings (DES) on the territory of the Murmansky block. a - «VES-Zeus-MHD» experiment (Zhamaletdinov, 2015); 6 - «Murman-2018» experiment (Zhamaletdinov et al., 2019); в - geoelectrical sections and models M1, M2, M3. The curves $\rho_{a}$ for models M1-M3 are given in Fig. 3 a and $3 \mathrm{~b} ; \Gamma-$ rheological profile, explaining the inversion results in Fig. 3 в. The remaining explanations are given in the text. 
дены на рисунке 3 в для трех моделей - M1, M2 и М3. Оптимальной представляется модель М2 с сопротивлением третьего слоя $10^{6} \mathrm{Oм} \cdot \mathrm{M}$.

На рисунке 3 г приведен реологический профиль, опирающийся на модель В.Н. Николаевского (1996) и поясняющий результаты инверсии, показанной в виде трех моделей геоэлектрического разреза на рисунке 38 . На рис. $3 a$ и 36 можно видеть, что верхний слой с резко переменными (пилообразными) изменениями значений Рока (они находятся возле обозначений 3ЕВС на рис. $3 a$ и ДЭ3 на рис. 3б) соответствует зоне хрупких разрушений, «brittle zone». На глубине 10 км на рис. 3в залегает граница «непроницаемости», где сопротивление резко возрастает до $10^{6}$ Омм. На рис. 32 границе «непроницаемости» соответствует граница BDT. В интервале глубин от 10 до 40 км находится область залегания плотных плохо проводящих горных пород повышенной вязкости (semi-ductile zone). Глубже 40 км (глубже границы Мохо) сопротивление понижается до $10^{4}$ Ом· м. Здесь, в интервале глубин от 40 до 80 км располагается область пластического состояния горных пород («ductile zone»). Глубже 80 км сопротивление опускается до $10^{3}$ Ом $\cdot$ м, свидетельствуя о повышении температуры до $600^{\circ} \mathrm{C}$. Давление при этом достигает 2 Гпа и породы находятся в истинно пластическом состоянии согласно (Николаевский, 1996).

Таким образом, по результатам выполненного исследования (по комплексу геоэлектрических данных и сверхглубокого бурения) впервые количественно установлено положение предполагаемой границы перехода между хрупким и квази-пластичным состояниями земной коры в виде границы условной «непроницаемости» и «непреодолимости» на глубине порядка 12 км.

\section{Благодарность}

Автор признателен к.ф.-м.н. А.Н. Шевцову за просмотр рукописи и ценные замечания, которые автор с благодарностью учел.

Работа выполнена при финансовой поддержке РФФИ, проект № 18-05-00528, а также в рамках госзадания Министерства образования и науки РФ - тема ГИ КНЦ РАН № 0226-2019-0052 и тема ЦЭС КНЦ РАН № 0226-2019-0067.

\section{Литература}

1. Ваньян Л.Л. Электромагнитные зондирования // М. Изд-во: Научный мир. 1997. 218c.

2. Гзовский М.В. Основы тектонофизики // М. Изд-во: Наука. 1975. 535 с.

3. Геоэлектрические исследования с мощным источником тока на Балтийском щите. Отв. редактор Велихов Е.П. М. Изд-во: Наука. 1989. 272 с.

4. Глазнев В.Н. Комплексные геофизические модели литосферы Фенноскандии // Апатиты. Изд-во: К\&M, 2003. $252 \mathrm{c}$.

5. Жамалетдинов А., Кулик С.Н., Павловский В.И., Рокитянский И.И., Таначев Г.С. Аномалия короткопериодных геомагнитных вариаций над структурой Имандра-Варзуга (Кольский полуостров). // Геофиз. журнал. 1980. Т. 2. N 1. С. 91-96.

6. Жамалетдинов А.А. Модель электропроводности литосферы по результатам исследований с контролируемыми источниками поля (Балтийский щит, Русская платформа) // Л. Изд-во: Наука. 1990. $159 \mathrm{c}$.

7. Жамалетдинов А.А. Электропроводность земной коры в районе СНЧ-антенны «Зевс» по результатам зондирований на постоянном и переменном токе (Мурманский блок) // Взаимодействие электромагнитных полей КНЧ-СНЧ диапазона с ионосферой и земной корой. Материалы I-го Всероссийского научно-практического семинара. Апатиты. 2015. С. 63-71. ISBN 978-5-902643-32-6.

8. Жамалетдинов А.А. Велихов Е.П., Шевцов А.Н., Скороходов А.А., Колобов В.В., Ивонин В.В., Колесников В.В. Эксперимент «Мурман-2018» по дистанционному зондированию с целью исследования границы «непроницаемости» на переходе между хрупким и пластичным состояниями кристаллической земной коры // Доклады Академии наук. 2019. Т. 486. № 3. С. 91-96. DOI: 10.31857/S0869-56524863359-364.

9. Жданов М.С., Френкель М.А. Миграция электромагнитных полей при решении обратных задач геоэлектрики // ДАН СССР. 1983. Т. 271 № 3. С. 589-594.

10. Николаевский В.Н. Катакластическое разрушение пород земной коры и аномалии геофизических полей // Известия РАН. Физика Земли. 1996. № 4. С. 41-50.

11. Садовский М.А. Опытные исследования механического действия ударной волны взрыва // Труды сейсмологического ин-та АН СССР. 1945 М.-Л. № 116. 
12. Шаров Н.В., Митрофанов Ф.П. Скоростные неоднородности литосферы Фенноскандинавского (Балтийского) щита // Доклады академии наук. 2014. Т. 454. № 2. С. 221-224.

13. Kirby S. \& Kronenberg A. Correction to 'Rheology of the lithosphere: selected topics' // Rev. Geophys. 25. P. $1680-1681$.

14. Korhonen H \& Porkka M.T. (1981). The structure of the Baltic Shield Region on the basis of DSS and earthquake data // Pure and Applied Geophysics. 1981. 119(6). P. 1093-1099.

15. Moisio K \& Kaikkonen P. The present day rheology, stress field and deformation along the DSS profile FENNIA in the central Fennoscandian Shield // Journal of Geodynamics. 2004. V. 38. P. 161-184.

16. Moisio K. Numerical lithospheric modelling rheology stress and deformation in the Centrak Fennoscandian Shield // Acad Dissert. Univ. of Oulu. 2005. 39 p.

17. Ranalli G. Rheology of the Earth // London. Allen and Unwin. 1987. 336 p.

18. Shevtsov A.N. (2019) Joint Interpretation of Magnetotelluric and CSAMT Data on the Kola Peninsula (Kovdor Area) // In: D. Nurgaliev \& N. Khairullina (eds.), Practical and Theoretical Aspects of Geological Interpretation of Gravitational, Magnetic and Electric Fields. Springer Proceedings in Earth and Enviramental Sciences, Springer. Cham. 2019. P. 23-30. https://doi.org/10.1007/978-3-319-97670-9_3. 